\title{
O diagnóstico da gestão de design por meio do objeto de design da informação: um estudo do desenvolvimento de infográficos educacionais na UNASUS-UFMA
}

\author{
Design management diagnosis through the information design object: a case study \\ on the educational infographics development process in UNASUS-UFMA
}

\author{
Bolívar Teston de Escobar
}

infografia sobre saúde, gestão de design, educação a distância, estudo de caso, UNASUS

\begin{abstract}
O presente artigo é uma síntese de uma pesquisa de mestrado cujo objetivo era propor recomendações para o desenvolvimento de infográficos para os materiais dos cursos a distância da UNASUS na perspectiva da gestão de design. Ela foi desenvolvida em três etapas: primeiramente, uma revisão da literatura busca trazer os fundamentos das temáticas envolvidas (infografia na área da saúde, educação a distância na área da saúde e gestão de design); a segunda etapa é um estudo de caso, tendo como objeto a estrutura da unidade da Universidade Federal do Maranhão da UNASUS, a Universidade Aberta do SUS. Esse estudo de caso envolve entrevistas e documentação para formular um diagnóstico da gestão de design envolvida no processo de design de infográficos utilizados no material didático dos cursos a distância ofertados pela instituição; a terceira e última etapa é uma proposição de recomendações para esse processo, com base nos pontos observados no diagnóstico à luz da literatura de gestão de design. Os resultados do estudo de caso mostram a percepção acerca do entendimento sobre o design gráfico na instituição, visualizado com o auxílio de gráficos comparativos. Além disso, percepções sobre os níveis de gestão de design são obtidos dos entrevistados, fornecendo material para discussão acerca desses resultados sob a óptica dos temas abordados na fundamentação teórica.
\end{abstract}

health infographics, design management, distance education, case study, UNASUS

\begin{abstract}
The present research aims to offer recommendations on design management for the infographics design process currently adopted in the Open University of the Brazilian Standard Public Healthcare System (UNASUS), with focus on the infographics produced in the Federal Universty of Maranhão (UFMA) office of the instituition. The study is conducted in three phases: first, the fundamentals of the themes envolved (health infographics, distance education about health and design management) are presented through bibliographical research. The following phase is a case study about the UNASUS-UFMA, making use of interviews and documentation in order to generate a diagnosis of the infographic design process in its positive and negative aspects; the third and last phase aims to deliver a list of improvement recommendations for this design process based on design management principles. The results show that the method used was successful in bringing different perceptions of the interviewees about the role of the graphic deisgn in the institution, as well as perceptions about the management levels of the other departaments involved in the process. These results are discussed, bringing the key-aspects of the institution and its processes to the light of the literature brought by the bibliographical research.
\end{abstract}

\section{Introdução}

O diagnóstico de gestão, conforme definem Dalbeto e Gonçalves (2013), é uma ferramenta utilizada por empresas e organizações que desejam uma avaliação ou método de dimensionamento de seu estado presente, com a finalidade de definir condições necessárias para atingir um novo estado. Conforme demonstra Wolff (2010), diagnósticos podem focar em aspectos de gestão de design, dado o potencial inovador da área e suas contribuições para a diferenciação em modelos de negócio (Kistmann, 2003; Mozota, Klopsch \& Costa., 2011).

Nessa área, diagnósticos geram estudos de caso que elucidam questões referentes o nível da atuação do design: se ele se encontra majoritariamente concentrado em situações

Anais do 9 CIDI e 9 CONGIC

Luciane Maria Fadel, Carla Spinillo, Anderson Horta, Cristina Portugal (orgs.)

Sociedade Brasileira de Design da Informação - SBDI

Belo Horizonte | Brasil | 2019

ISBN 978-85-212-1728-2
Proceedings of the 9th CIDI and 9th CONGIC Luciane Maria Fadel, Carla Spinillo, Anderson Horta, Cristina Portugal (orgs.)

Sociedade Brasileira de Design da Informação - SBDI Belo Horizonte | Brazil | 2019 ISBN 978-85-212-1728-2 
operacionais, ou se, graças à políticas de gestão que reconhecem esse seu potencial, encontra-se presente também nas estratégias da instituição.

No estudo específico apresentado pelo presente artigo, o escritório da Universidade Federal do Maranhão da Universidade Aberta do SUS (UNASUS-UFMA) foi a unidade-caso escolhida para a aplicação de um diagnóstico da gestão de design com os atores envolvidos no desenvolvimento de infográficos para educação a distância ( $\mathrm{EaD})$. Na área da saúde, a EaD é uma importante aliada na atualização médica dos profissionais em atuação justamente por ser acessível nos lugares por vezes isolados nos quais eles encontram-se alocados (Leite et al., 2010). Ou seja, desde 2008 a UNASUS esteve engajada no propósito da formação continuada de médicos, enfermeiros e outros atuantes da área da saúde por meio do da concepção e divulgação de materiais informacionais.

Dado esse contexto, como a perspectiva da gestão de design poderia contribuir para o processo de produção de infográficos para EaD na área da saúde na UNASUS? O estudo da infografia no âmbito do design da informação é relativamente recente (e.g., Lima, 2015; Miranda, 2013; Andrade, 2014), e ocorre principalmente através da identificação de sua sintaxe gráfica com teorias de autores como Twyman (1982) e Horn (1992). Entretanto, a aplicação de infográficos em áreas além do jornalismo ainda é pouco explorada academicamente e na literatura sobre o tema.

Apesar da pertinência da gestão do design para o design gráfico/da informação, nota-se uma concentração de estudos sobre Gestão de Design em duas áreas: design de produção e design de produto, conforme a revisão bibliográfica feita por De Souza Libânio e Amaral (2011). Nesta, os autores apontam uma gama variada de objetivos nos 63 trabalhos analisados, sendo a principal tendência (32\%) a investigação ou avaliação da gestão de design em empresas e sua aplicação em estudos de caso. Assim, nota-se a existência de uma lacuna de estudos sobre gestão de design voltados ao design da informação em Educação a Distância, e em particular na produção de conteúdo informacional na área de saúde.

O presente artigo traz um resumo sobre o estudo realizado durante a condução de uma pesquisa de mestrado em Design de Sistemas de Informação, no programa de pós-graduação em Design da UFPR. Com o objetivo de propor recomendações para o processo de desenvolvimento de infográficos sobre saúde para EaD na UNASUS-UFMA (na perspectiva da gestão do design), o método do estudo de caso conforme o proposto por Yin (2005) foi o escolhido, sendo a pesquisa enquadrada como de natureza aplicada (Gil, 2002), já que visava atuar sobre um problema prático e objetivamente localizado no mundo real.

Os resultados trazem informações interessantes acerca do entendimento da gestão de design em uma organização voltada para a educação e a atualização médica: os dados coletados foram organizados em visualizações que permitiram detectar os contrastes do entendimento do papel do design gráfico entre as diferentes camadas da gestão da instituição (conforme também demonstra Wolff, 2010). Além disso, pode-se observar o potencial que o estudo focado em um objeto do design da informação traz para a área da gestão de design, ao permitir que inferências sobre a cultura de design presente na organização sejam feitas a partir da observação da atuação dos profissionais dentro do seu processo produtivo.

\section{Método do estudo de caso}

A pesquisa qualitativa realizada dividiu-se em três etapas: a primeira compreendia uma pesquisa bibliográfica, com a coleta de dados advinda de revisão de literatura, cujo objetivo principal era criar o que Yin (2005) chama de "teoria para o estudo de caso". Desta teoria, extraem-se as diretrizes para conduzir estudos de campo e coletas de dado com as pessoas envolvidas na unidade-caso. No caso desta pesquisa, a revisão bibliográfica foi usada para adaptar um modelo de diagnóstico de gestão, composto pelos questionários estruturados propostos por Wolff (2010), no qual 22 afirmações foram qualificadas pelos entrevistados com pontuações de 1 (concordo totalmente) a 5 (discordo totalmente). Para complementar, um segundo protocolo e semi-estruturado foi adaptado das questões sobre níveis de gestão de Kistmann (2003), com o conteúdo das perguntas ditado pelas referências bibliográficas estudadas. 
A segunda etapa compreendeu (1) a coleta de dados oriunda das entrevistas com os colaboradores da UNASUS-UFMA direta ou indiretamente envolvidos na produção de infográficos para EaD; (2) A análise desses dados, obtida por meio da organização dos participantes em grupos e cruzando as respostas entre os participantes e os grupos, de forma a visualizar as divergências e concordâncias em relação à gestão de design (Wolff, 2010). Para as perguntas do protocolo semi-estruturado, as respostas foram codificadas em chaves de interpretação (DeCuir-Gunby et al., 2011) para gerar os insights necessários para criar um encadeamento de evidências para o estudo de caso (Yin, 2005); (3) A extração de sentido da análise, cruzando as respostas de ambos os protocolos e fazendo a correlação com as informações que fundamentam a teoria do estudo de caso, além da consideração de documentos que auxiliem a compreender a organização interna da unidade caso, formando, portanto, uma triangulação de informações.

A terceira e última etapa foi voltada para a geração de recomendações para o desenvolvimento de infográficos com base nos padrões e tendências observadas no estudo de caso. Justamente por isso, o estudo de caso se caracteriza como restrito a uma situação singular, não sendo, portanto, seus resultados generalizáveis para todas as organizações interessadas em recomendar melhorias para seus processos de design da informação.

\section{Base teórica para a aplicação do estudo de caso}

A construção de uma "teoria" para a aplicação dos protocolos do estudo de caso (Yin, 2005) envolveu compreender a correlação entre os principais temas pertinentes ao desenvolvimento de infográficos para a educação a distância: a relação da infografia com o design da informação na área da saúde, o papel do desenvolvimento instrucional na educação a distância, e a gestão de design para materiais como o infográfico.

Primeiramente foi feita uma Revisão Bibliográfica Sistemática (RBS) que serviu como ponto de partida para buscar fontes e referências atualizadas sobre os temas elencados. A RBS tem o objetivo de ilustrar o estado-da-arte ao trazer à tona pesquisas similares feitas recentemente, bem como lacunas a serem preenchidas por desdobramentos a elas (Conforto et al, 2011). As fontes e artigos relevantes foram arquivados e a fundamentação teórica da pesquisa foi escrita em capítulos que forneceram requisitos para a aplicação das entrevistas.

\section{Infográficos na área de saúde e seu potencial uso na EaD}

O entendimento da inserção dos infográficos em cursos a distância na área da saúde passa, primeiramente, pelo entendimento do que são infográficos e como estes se configuram. A infografia pode ser compreendida como uma forma de composição visual que possibilita a integração de elemento verbais, pictóricos e esquemáticos para transmitir mensagens e elucidar conceitos complexos (Lima, 2009).

Meggs (2011) sugere que a base da infografia é a geometria analítica, como desenvolvida e usada pela primeira vez por René Descartes (1596-1650). Segundo o autor, Descartes traçou duas linhas perpendiculares transversais - o eixo " $x$ " e o eixo " $y$ " do plano cartesiano. Tal representação foi adaptada pelo cientista escocês William Playfair (1759-1823) para converter dados estatísticos em gráficos com a ajuda de símbolos, com o intuito de popularizar e facilitar a interpretação de informações econômicas. Florence Nightingale (1820-1910) aplicou a técnica de visualização de dados para construir gráficos demonstrando que doenças causadas pelas más condições de higiene nos hospitais resultavam em mais mortes do que ferimentos de guerra.

Atualmente, segundo Lima (2015), a infografia é uma área inclusa no estudo do design da informação, justamente pelo seu propósito: a otimização do processo de aquisição da informação:

A principal função informacional do infográfico tem sido trazer, para primeiro plano, uma maior compreensão visual-gráfica da informação muitas vezes ignoradas na tradição da linguagem verbal.

(Lima, 2015, p. 125) 
Por causa dessa função, infográficos são uma ferramenta útil em materiais educacionais. Ainsworth (2008) defende que o uso de representações visuais é fundamental para comunicar informações em formatos que são mais apropriados às necessidades dos alunos. Para Pessoa e Maia (2015), nos ambientes virtuais de aprendizagem, a presença de hiperlinks permite que os educadores empreguem diferentes recursos para compor o material didático. Neste sentido, o uso de infográficos é uma forma de representação de conteúdos para auxiliar a comunicação, permitindo recursos como a interação.

O entendimento de como produzir infográficos para a educação a distância na área da saúde fez com que esta pesquisa se voltasse para o processo de design de infográficos. $\mathrm{Na}$ $\mathrm{EaD}$, o modelo ADDIE é o adotado para desenvolver os materiais instrucionais, já que ele engloba, segundo Branch e Kopcha (2014), fases de análise, design, desenvolvimento, implementação e avaliação de forma cíclica, intercaladas por revisões desses materiais. Cruzando as etapas do modelo ADDIE com os objetivos das etapas dos principais processos de design de infográficos estudados nesta pesquisa, pode-se obter o seguinte quadro-síntese:

Quadro 1: Síntese dos elementos centrais do modelo ADDIE (Branch e Kopcha, 2014, traduzido pelo autor) em comparação com os aspectos da infografia levantados pelos autores da literatura do tema.

\begin{tabular}{|c|c|c|c|c|}
\hline \multicolumn{5}{|c|}{ Objetivos das etapas do Modelo AADDIE } \\
\hline Análise & Design & Desenvolvimento & Implementação & Avaliação \\
\hline $\begin{array}{l}\text { Identificar e } \\
\text { delimitar a } \\
\text { necessidade } \\
\text { instrucional }\end{array}$ & $\begin{array}{l}\text { Verificar a } \\
\text { performance } \\
\text { desejada, bem } \\
\text { como os } \\
\text { métodos de } \\
\text { teste } \\
\text { apropriados }\end{array}$ & $\begin{array}{l}\text { Gerar e validar os } \\
\text { recursos de } \\
\text { aprendizagem }\end{array}$ & $\begin{array}{l}\text { Preparar o } \\
\text { ambiente de } \\
\text { aprendizagem e } \\
\text { engajar os } \\
\text { estudantes }\end{array}$ & $\begin{array}{l}\text { Avaliar a } \\
\text { qualidade dos } \\
\text { produtos e } \\
\text { processos de } \\
\text { instrução, tanto } \\
\text { antes quanto } \\
\text { após a } \\
\text { implementação }\end{array}$ \\
\hline \multicolumn{5}{|c|}{ Tomadas de decisão em infográficos na área de saúde } \\
\hline $\begin{array}{l}\text { Identificar a } \\
\text { pergunta que } \\
\text { deseja ser } \\
\text { respondida com } \\
\text { o infográfico } \\
\text { (Moraes, 2013), } \\
\text { bem como sua } \\
\text { abordagem } \\
\text { (Lankow et al., } \\
\text { 2012). }\end{array}$ & $\begin{array}{l}\text { Identificar as } \\
\text { ferramentas } \\
\text { disponíveis para } \\
\text { a criação da } \\
\text { peça } \\
\text { (Rajamanickam, } \\
\text { 2005). }\end{array}$ & $\begin{array}{l}\text { Levantar os } \\
\text { aspectos formais } \\
\text { (Miranda, 2013) e } \\
\text { requisitos (Filatro, } \\
\text { 2008). Iniciar o } \\
\text { processo de } \\
\text { desenvolvimento do } \\
\text { infográfico. }\end{array}$ & $\begin{array}{l}\text { Selecionar o } \\
\text { método } \\
\text { comunicacional } \\
\text { (Rajamanickam, } \\
\text { 2015) e a } \\
\text { modalidade } \\
\text { (Ribas, 2004). }\end{array}$ & $\begin{array}{l}\text { Obter feedback } \\
\text { e aperfeiçoar } \\
\text { etapas do } \\
\text { processo. }\end{array}$ \\
\hline
\end{tabular}

O que liga esse assunto com a gestão de design é buscar as pessoas envolvidas em cada etapa do modelo ADDIE e como elas se relacionam com o objeto do infográfico. Para Okada e Santos (2003), essa organização pode configurar-se de modo pluridisciplinar, multidisciplinar ou interdisciplinar, sendo esta última uma configuração voltada para a troca ativa de informações entre os diferentes saberes em uma equipe de desenvolvimento de materiais para EaD. O infográfico é um material produzido a várias mãos, que compreende temas complexos e diferentes suportes visuais e tecnológicos para sua configuração: quando produzido como material de $\mathrm{EaD}$, questionar onde encontra-se o designer no fluxo dessa produção aproxima o problema da área da gestão de design.

\section{A gestão de design e o design de infográficos para $\mathrm{EaD}$ na área de saúde}

Segundo Best (2006), a gestão de design refere-se ao gerenciamento de projetos de design: projetos pagos por clientes, negócios ou organizações, e conduzidos por designers, equipes de design ou por consultores de design. Tratando o infográfico educacional como um produto de multimídia destinado aos Ambientes Virtuais de Aprendizagem (AVA), a instituição de educação a distância precisa movimentar pessoas, recursos e ferramentas para integrar o processo de concepção desses materiais ao plano de trabalho já em andamento.

Mozota, Klopsch e Costa (2011) sugerem que a integração do design nas corporações seja vista em níveis de gestão: 
- Design operacional: materialização dos objetivos estratégicos da empresa em produtos e pontos de contato com os clientes e consumidores.

- Design tático: decisões estratégicas são interpretadas em decisões administrativas relacionadas ao design. Segundo Mozota et al. (2011), nesse nível o design não é apenas um produto ou um objeto, mas um departamento ou uma função dentro da organização.

- Design estratégico: Segundo Teixeira et al. (2011), o planejamento estratégico consiste em antever os estados futuros da organização e os procedimentos que serão empregados para chegar até eles. Para Mozota et al. (2011), a gestão estratégica do design tem quatro objetivos fundamentais: visualizar a estratégia empresarial; procurar competências centrais; reunir informações de mercado e inovar em processos de gerenciamento.

Para diagnosticar o estado da gestão de design de infográficos na UNASUS-UFMA, achamos coerente buscar visualizar a correlação do desenvolvimento de infográficos com os níveis de gestão. Cada processo estudado pode contribuir em etapas para o outro, cabendo, portanto, à equipe decidir o que empregar para o infográfico dependendo do objetivo ou situação na qual ele será desenvolvido.

Outro ponto é a clara distinção entre etapas e a prevalência do papel do designer no nível operacional. É válido, portanto, defender que os processos de design de infográficos demandam que designers estejam presentes atuando junto aos profissionais enquadrados na atuação estratégica e tática da concepção desses materiais, já que decisões tomadas nesses níveis impactam diretamente o resultado final operacional, dada a presença de fatores como a participação do usuário, fonte essencial de inputs e requisitos para o design dos infográficos. Em síntese, o desenvolvimento de infográficos apresentam potencial para inclusão do designer gráfico em níveis estratégicos de tomada de decisão.

\section{Aplicação e análise das entrevistas}

Estudos de caso começam com uma caracterização da unidade-caso. A origem da UNASUSUFMA está no Decreto oㅜ 7.385, de 8 de dezembro de 2010, que teve como propósito a instituição da Universidade Aberta do Sistema Único de Saúde, por meio de uma iniciativa do Ministério da Saúde, em parceria com as esferas estadual e municipal, instituições públicas de ensino superior e unidades internacionais. Visando a formação continuada dos profissionais da área, a instituição ofertaria cursos de pós-graduação e de extensão universitária a distância através de plataformas virtuais. Conforme já relatado por Soares (2015), o material desenvolvido é de acesso livre às instituições de ensino e estudantes, disponibilizado em bibliotecas virtuais e/ou outras mídias tais como CD-ROM, DVD e impressos.

De acordo com o Relatório de Gestão da UNASUS (2016), a Universidade Federal do Maranhão (UFMA) foi uma das universidades pioneiras da rede, tendo seu ingresso em 2009, tendo desde então disponibilizado mais de 700 recursos educacionais na plataforma ARES. A participação da instituição sempre foi vista como exemplar e de grande impacto dentro da rede de IES:

A UNA-SUS/UFMA iniciou a produção dos seus primeiros cursos de especialização aprendendo com as IES que já integravam a Rede UNA-SUS há mais tempo. Visitou-as, aprendeu e reutilizou algumas de suas soluções. Com essa aprendizagem, fortaleceu sua equipe capacitando-a e apostou no investimento em pesquisa aplicada para desenvolver suas próprias soluções, tanto em tecnologia quanto em metodologia. (UNA-SUS, 2016, p. 14).

O extenso portfolio de cursos e objetos de aprendizagem lançados pela UNASUS-UFMA é classificado como open-source, ou seja, aberto para a utilização e distribuição gratuita por alunos ou outras instituições parceiras.

A equipe responsável pelo desenvolvimento de infográficos localiza-se no núcleo pedagógico da instituição, e é formada por pedagogos, designers gráficos, revisores e desenvolvedores (analistas de sistemas e profissionais de tecnologia da informaç̧ão). Esse núcleo faz parte da Coordenação de Produção (uma das duas "frentes" da UNASUS-UFMA, 
sendo a outra a Coordenação de Oferta). A Coordenação e Produção é responsável por lançar editais para os conteudistas (terceirizados) que responderão com textos produzidos para satisfazer demandas que partem, sobretudo, do Ministério da Saúde. Antes da produção do material educacional iniciar de fato, os textos passam por uma validação profissional e por uma primeira bateria de revisões e normatizações feitas com a ajuda de uma equipe especializada em biblioteconomia.

Por meio de uma primeira consulta com a coordenadora geral de produção da UNASUSUFMA, os atores diretamente envolvidos com a produção de infográficos foram identificados. Em seguida foi definido um cronograma de entrevistas conforme a disponibilidade de cada um. O quadro 2 mostra quem são os stakeholders, sua formação e cargo dentro da instituição. Cada departamento da UNASUS-UFMA diretamente ligado ao processo teve 2 funcionários convidados para entrevistas, além dos gestores, totalizando, portanto, 8 entrevistados para a obtenção do diagnóstico da gestão de design.

Quadro 2: Atores envolvidos no processo de desenvolvimento de infográficos da UNASUS-UFMA.

\begin{tabular}{l|l|l} 
Entrevistado & Departamento & Cargo \\
\hline Dg1 & Comunicação & Designer gráfico \\
\hline Dg2 & Comunicação & Designer gráfico \\
\hline Di1 & Desenvolvimento Instrucional & Supervisão de Design Instrucional \\
\hline Di2 & Desenvolvimento Instrucional & Designer Instrucional \\
\hline Ti1 & Tecnologia da Informação & Coordenador de Tecnologia da Informação \\
\hline Ti2 & Tecnologia da Informação & Analista de sistemas \\
\hline Ge1 & Produção & Coordenador de Produção \\
\hline Ge2 & Coordenação Geral & Coordenador geral \\
\hline
\end{tabular}

Para identificar o processo de desenvolvimento de infográficos, perguntas acerca das decisões pertinentes a esse tipo de material no fluxo de desenvolvimento de materiais da UNASUS-UFMA foram feitas igualmente a todos os participantes elencados. Os oito entrevistados ( $\mathrm{Dg} 1$ e 2, referentes aos designers gráficos; Di1 e 2, referentes aos pedagogos; Ti1 e 2, referentes aos técnicos da informação; e Ge1 e 2, referentes aos gestores) foram convidados a relatar seus papéis dentro desse fluxo de desenvolvimento de materiais educacionais, bem como sua visão sobre o papel que o design gráfico desempenha. Após a condução das entrevistas com os protocolos, visualizações das respostas foram geradas em gráficos de radar. Esses gráficos permitiram encontrar divergências entre diferentes esferas na organização da instituição, ao cruzar respostas tanto dos designers responsáveis quanto dos demais profissionais envolvidos na produção de infográficos.

\section{Resultados e discussões das entrevistas}

A sistemática de avaliação de Wolff (2010) permite apontar as divergências entre as pessoas e os grupos. O que pode-se observar foi uma grande inclinação a encarar a importância do design para a produção dos materiais, mas uma realidade que não necessariamente traduzia esse intento. Por exemplo, ao comparar as respostas dos entrevistados pertencentes ao grupo de gestores (figura 1), podemos observar uma concordância na afirmação 3 ("Designers gráficos tem independência para criar novas soluções visuais para os materiais dos cursos da UNASUS-UFMA."), o que demonstra um reconhecimento por parte da gestão para a contribuição em potencial que o design da informação pode trazer para os materiais didáticos por meio de objetos como a infografia. Entretanto, a afirmação 22 ("O mais importante quando se trata de design gráfico é a aparência que ele dá aos materiais da UNASUS-UFMA") aparece com um grande contraste entre as respostas. Isso indica um desentendimento sobre o direcionamento desses profissionais no processo de desenvolvimento dos materiais educacionais. 
Figura 1: Gráfico de radar comparando as respostas do grupo de gestores (Ge1 e Ge2). Elaborado pelo autor com base em Wolff (2010).

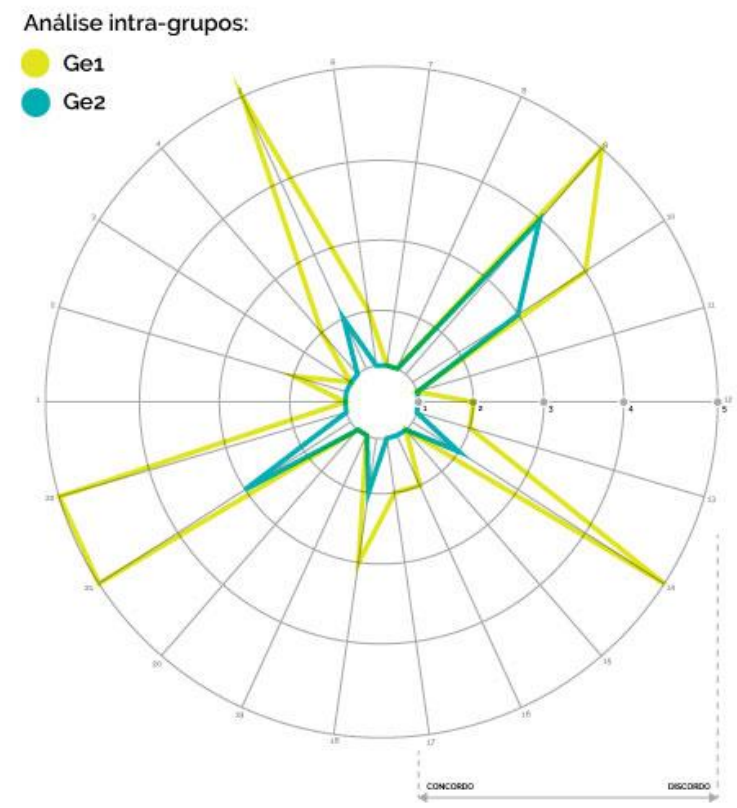

Esse tipo de comparação foi feito repetidas vezes entre pessoas do próprio grupo e entre grupos distintos, para detectar os diferentes padrões que configuram o diagnóstico da gestão de design. Para visualizar as oscilações de respostas em cada pergunta individualmente, a visualização foi feita horizontalmente. Isso trouxe insights interessantes: a afirmação 14 ("O processo de criação de novos conteúdos na UNASUS-UFMA integra designers gráficos em etapas de planejamento e estratégia."), teve respostas contrastantes entre os entrevistados (figura 2). Isso pode ser indicativo de uma possível incerteza quanto ao posicionamento dos designers gráficos nas dinâmicas do processo de produção e nas tomadas de decisão desse processo.

Figura 2: Gráfico horizontal comparando as respostas à afirmação 14 pelos oito 8 entrevistados. Elaborado pelo autor.

0 processo de criação de novos conteúdos na UNASUS-UFMA integra designers gráficos em etapas de planejamento e estratégia.

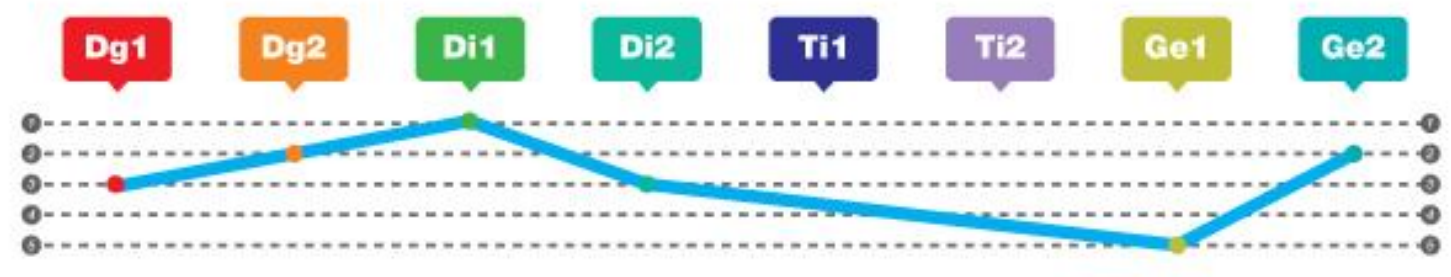

A afirmação que menos gerou oscilação foi a 7 ("Imagens, diagramas e outras peças gráficas são essenciais para os materiais disponibilizados pela UNASUS-UFMA" - figura 3). 
Figura 3: Gráfico horizontal comparando as respostas à afirmação 7 pelos oito 8 entrevistados. Elaborado pelo autor.

Imagens, diagramas e outras peças gráficas são essenciais para todos os materiais disponibilizados pela UNASUS-UFMA.

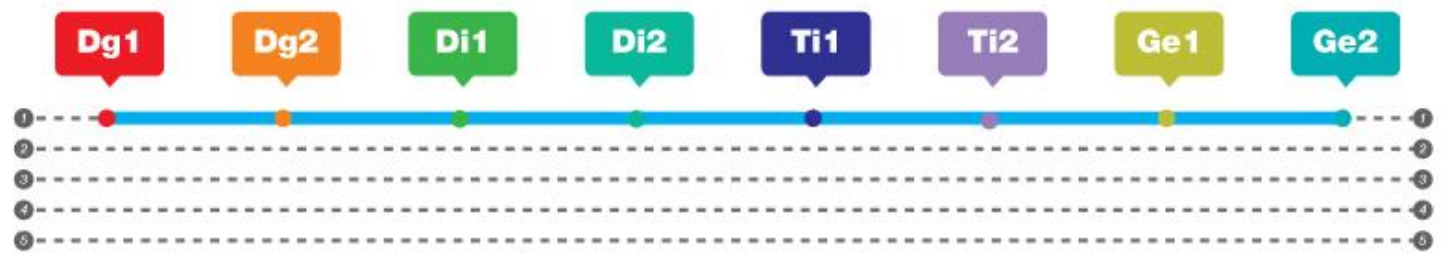

O que essa unanimidade demonstra é que existe a noção, entre todos os entrevistados, que o trabalho desempenhado pelos designers gráficos na composição de peças gráficas é essencial para a constituição dos materiais dos cursos à distância.

Além deste protocolo, outro questionário acerca dos níveis de gestão (adaptado de Kistmann, 2003) também foi aplicado, e as respostas, ao serem analisadas, fornecem dados que também foram cruzados com as tendências observadas no questionário anterior. Esse questionário trouxe informações como a visão de cada entrevistado sobre os pontos fracos e fortes da organização, opiniões acerca do processo de design dos infográficos, do papel do design dentro do fluxo de trabalho da equipe e outras questões relacionadas a tempo, recursos, dinâmica do trabalho e valor visto pelos funcionários em torno do que se entende por "design da informação". Por exemplo, uma das questões era "Qual o papel do Design Gráfico dentro da organização?", o que gerou respostas codificadas como um entendimento do design majoritariamente encerrado em questões operacionais, pouco aproximado do estratégico da instituição.

Outro elemento detectado graças ao protocolo foi a baixa participação de usuários no processo de desenvolvimento. A pergunta 9 ("Existe participação no desenvolvimento dos públicos-alvo dos materiais (alunos, professores)?") recebeu como maioria das respostas uma negação: os usuários e alunos dos cursos da UNASUS-UFMA não estão inseridos na criação dos materiais. $O$ único contato, segundo os entrevistados, é por uma ferramenta de feedback inserida na interface dos Ambientes Virtuais de Aprendizagem. Essa ferramenta, no entanto, não é utilizada pela maior parte dos alunos: o feedback é proveniente de uma porcentagem baixa de usuário.

Para comparar esses resultados com a literatura que formou a teoria do estudo de caso, podemos mencionar alguns pontos relevantes dessa triangulação.

Okada e Santos (2003), em sua descrição da configuração interdisciplinar do fluxo de produção e materiais para EaD, evidenciam uma fluidez no posicionamento dos profissionais envolvidos como benéfica. Do ponto de vista da gestão de design descrita por Mozota et al. (2011), as implicâncias da adoção desta configuração inferem na participação dos designers gráficos em níveis além do operacional.

Dentre as vantagens de configurações interdisciplinares está a aproximação do público das tomadas de decisão quanto aos materiais, como também por deixarem uma dinâmica fluída na equipe e, portanto, facilitar o surgimento de novas soluções e inovações. Do ponto de vista dos níveis de gestão de design expostos por Mozota et al. (2011), é possível inferir que a organização multidisciplinar empodera os participantes do processo em papéis táticos e estratégicos, além do operacional, que restringe-se ao manuseio técnico e materialização das decisões tomadas.

Retomando o exemplo do modelo ADDIE (Filatro, 2008) em comparação com as decisões da infografia (vide quadro 1), é possível constatar o contraste entre as etapas desse modelo com a concentração de afazeres nas mãos do departamento de Desenvolvimento Instrucional que ocorre na UNASUS-UFMA. O modelo abre possibilidades para a incorporação de materiais complexos como infográficos ao fluxo de produção de uma organização de EaD, mas essa incorporação demanda que várias decisões pertinentes ao design gráfico precisem ser tomadas.

Anais do 9 Congresso Internacional de Design da Informação | CIDI 2019

Proceedings of the 9th Information Design International Conference

Anais do $9^{\circ}$ Congresso Nacional de Iniciação Científica em Design da Informação | CONGIC 2019

Proceedings of the $9^{\text {th }}$ Information Design Student Conference 
Segundo Best (2006), a implementação do design em uma organização segue por etapas que indicam o grau de inserção nos níveis organizacionais. A opção pela infografia, conforme observado, tende a apresentar etapas em seus processos que tragam o design gráfico para além do operacional.

Em resumo, os pontos detectados na investigação do estudo de caso demonstram os contrastes entre o que é percebido sobre o design gráfico e o que é de fato feito sobre ele em termos de gestão. Nesse sentido, a infografia assume um ponto-chave na pesquisa, que é o de comunicar potenciais melhorias para o processo de inclusão da design como um todo nos níveis estratégicos da organização: é lançando um olhar holístico sobre o desenvolvimento do objeto de design da informação que o diagnóstico da gestão de design se revela.

\section{Considerações finais}

O estudo de caso resumido no presente artigo produziu cerca de 12 horas de entrevistas, somando todo tempo investido na coleta de dados com os oito colaboradores da UNASUSUFMA.

O resultado apontou que: (a) existe um fluxo de desenvolvimento de materiais educacionais na UNASUS-UFMA que inicia-se na demanda advinda do Ministério da Saúde ou de outros órgãos. Essa demanda gera textos e conteúdos que são transformados por desenvolvedores instrucionais e implementados por técnicos da informação. Embora haja possibilidade de participação ativa dos designers gráficos, eles acabam sendo empregados em participações pontuais sob demanda; (b) existem muitas divergências no entendimento que esses departamentos e a gestão tem sobre o design gráfico, especialmente no foco dado aos infográficos. Essas divergências ocorrem tanto dentro dos departamentos quanto entre eles, apontando para uma distância entre o que se pensa sobre design e o que se faz sobre design na organização; (c) existem diferentes pesos nas atuações de cada departamento envolvido no desenvolvimento de infográficos nos níveis e gestão da UNASUS. Enquanto o desenvolvimento instrucional e a tecnologia da informação atuam estrategicamente, o design gráfico fica mais concentrado no nível operacional; (d) a óptica da gestão de design pode apontar oportunidades de gerenciamento para processos de design de infográficos para EaD por meio da análise do contexto desses processos e das pessoas que participam dele.

É válido ressaltar que foi observado, na coleta e análise dos dados dessas respostas, que as discussões aqui apresentadas são pertinentes aos níveis operacionais e principalmente táticos da organização do design na UNASUS-UFMA, e que o termo "estratégico" é empregado para se referir às estratégias referentes a cada etapa do processo de desenvolvimento de infográficos, e não somente ao âmbito estratégico da gestão, conforme será demonstrado.

A lista de recomendações para o processo de desenvolvimento de infográficos da UNASUSUFMA, gerada como objetivo da pesquisa de mestrado, traz apontamentos voltados para possibilitar um aproveitamento mais estratégico das competências do designer de infográficos dentro do fluxo de produção dos materiais educacionais. Entretanto, um desdobramento merece atenção: o potencial de materiais complexos, como infográficos, como chaves para o entendimento da gestão de design em organizações. Embora já tenhamos mencionado que o presente estudo de caso não permite generalizações, a constatação desse desdobramento é um interessante resultado da escolha da sistemática de Wolf (2010) para a condução das entrevistas. Estudos futuros poderiam aprofundar o entendimento sobre o design da informação e suas materializações em outros contextos de produção, descrevendo e interpretando as relações de gestão do seu entorno produtivo.

\section{Agradecimentos}

A pesquisa de mestrado aqui apresentada não teria sido possível sem a orientação da professora Carla Galvão Spinillo, que trouxe as principais referências e abordagens metodológicas. Além disso, agradeço novamente à equipe da UNASUS-UFMA, que, na época, se mostrou extremamente aberta e disponível para fornecer os dados desse estudo de caso. 


\section{Referências}

Ainsworth, S. (2008) The educational value of multiple representations when learning complex scientific concepts. Visualization: Theory and practice in science education . Springer Netherlands

Andrade, R. C. (2014). Infográficos animados e interativos em saúde: Um estudo sobre a compreensão de notícias. Dissertação (Mestrado em Design). Universidade Federal do Paraná, Curitiba.

Best, K. (2006). Design Management: managing design strategy, process and Implementation. Lausanne: AVA Book.

Branch, R. M., \& Kopcha, T. J. (2014) Instructional design models. In: Handbook of research on educational communications and technology. Springer New York. p. 77-87.

Brasil. (2016) Resolução CNE/CES 1/2016. Diário Oficial da União, Brasília, 14 de março de 2016, Seção1, págs. 23-24.

Conforto, E. C., Amaral, D. C. \& Silva, S. L. (2011) Roteiro para revisão bibliográfica sistemática: aplicação no desenvolvimento de produtos e gerenciamento de projetos. In: 8ํ Congresso Brasileiro de Gestão de Desenvolvimento de Produto-CBGDP.

Dalbeto, L. C., \& Gonçalves, M. (2013). A contribuição do diagnóstico para traçar a estratégia da empresa-Estudo de caso de uma empresa de confecção. Projetica, v. 4, n. 1, p. 23-48.

Decuir-Gunby, J. T., Marshall, P. L. \& Mcculloch, A. W. (2011). Developing and using a codebook for the analysis of interview data: An example from a professional development research project. Field methods, v. 23, n. 2, p. 136-155.

De Souza Libanio, C., \& Amaral, F. G. (2011). Aspectos da gestão de design abordados em dissertações e teses no Brasil: uma revisão sistemática. Revista Produção Online, v. 11, n. 2, p. 565-594.

Filatro, A. (2008). Design instrucional na prática. São Paulo: Pearson Prentice Hall.

Gil, A. C. (2002). Como elaborar projetos de pesquisa. São Paulo: Atlas.

Horn, E. (1998). Visual Language: Global communication for the 21st Century. Washington: Macro VU, Inc.

Kistmann, V. B.; Wolf, B. (2003). Questionário de avaliação do nível de apropriação da gestão do design nas micro, pequenas e médias empresas. CNPq. Florianópolis: FIESC. Mimiografado.

Lankow, J.; Ritchie, J.; Crooks, R. (2012). Infographics: The power of visual storytelling. New Jersey: John Wiley \& Sons.

Leite, M.T.M. et al. (2010). Educação médica continuada online: potencial e desafios no cenário brasileiro. Revista Brasileira de Educação Médica. Rio de Janeiro, n.34, p.141149.

Lima, R. C. (2009). Análise da infografia jornalística. Dissertação (Mestrado em Design). Universidade do Estado do Rio de Janeiro, Escola Superior de Desenho Industrial, Rio de Janeiro.

Lima, R. C. (2015). O que é infografia jornalística? Revista InfoDesign v. 12, n. 1: 111-127.

Meggs, P. B., \& Purvis, A. W. (2011). Meggs' history of graphic design. New Jersey: John Wiley \& Sons.

Miranda, F. (2013). Animação e interação na infografia jornalística: Uma abordagem do Design da Informação. Dissertação (Mestrado em Design). Universidade Federal do Paraná, Curitiba.

Moraes, A. (2013). Infografia: história e projeto. São Paulo: Blucher.

Anais do 9ํ Congresso Internacional de Design da Informação | CIDI 2019 
Escobar, B. T. | O diagnóstico da gestão de design por meio do objeto de design da informação.

Mozota, B., Klöpsch, C., \& Costa, F. (2011). Gestão do design: usando o design para construir valor de marca e inovação corporativa. Porto Alegre: Bookman.

Okada, A. P., \& Santos, E. O. (2003). Articulação de saberes na EAD: por uma rede interdisciplinar e interativa de conhecimentos. In: Da Silva, M. A. Educação online: teorias, práticas, legislação, formação corporativa. São Paulo: Edicoes Loyola.

Pessoa, A. R., \& Maia, G. G. (2015). A infografia como recurso didático na Educação à Distância. Temática, v. 8, n. 5.

Rajamanickam, V. (2005). Infographics Seminar Handout. Disponível em $<$ http://www.albertocairo.com/infografia/noticias/2005/infographichandout.pdf>. Acesso em 20 de Março de 2016.

Soares, S. S. P. (2015). Elaboração de materiais científicos educacionais multimídia na área da saúde utilizando conceitos de design gráfico de interfaces, usabilidade e ergonomia. Tese de Doutorado. Programa de Pós-Graduação em Clínica Cirúrgica do Setor de Ciências da Saúde da Universidade Federal do Paraná.

Teixeira, S (2011). Gestão estratégica. Lisboa: Escolar Editora, p. 255-273.

Twyman, M. (1982). The graphic presentation of language. Information design journal, v. 3, n. 1 , p. 2-22.

Universidade Aberta do SUS - UNA-SUS. (2016) Relatório de Gestão, 2010-2015. 1. a edição.

Wolff, F. (2010). Sistemática de avaliação da gestão de design em empresas. Tese de Doutorado, Engenharia de Produção. Universidade Federal do Rio Grande do Sul.

Yin, R. (2005). Estudo de caso: planejamento e métodos. 3. ed. Porto Alegre: Bookman.

\section{Sobre o autor}

Bolívar Teston de Escobar, MsC, UFPR, Brasil <bolivarescobar@gmail.com> 